\title{
Comparison of the effects of laser and ultrasound treatments on experimental wound healing in rats
}

\author{
Hüseyin Demir, MD; Solmaz Yaray, MD; Mehmet Kirnap, MD; Kadir \\ Yaray, PhD
}

Department of Physical Medicine and Rehabilitation and Department of Radiation Oncology, Erciyes Üniversitesi, Kayseri, Turkey; Kayseri State Hospital, Kayseri, Turkey

Abstract - A randomized controlled study investigated the effects of ultrasound and laser treatments on wound healing in rats. The duration of the inflammatory phase decreased with both laser and ultrasound treatments; however, laser was more effec- tive than ultrasound, with more significant results. The prolifera- tion phase showed, for both treatments, an increase in the level of hydroxyproline and the number of fibroblasts, as well as stimula- tion of the collagen synthesis and the composition. Laser treat- ment was again more effective than ultrasound. The wound breaking strength was significantly higher with both treatments, and no statistically significant difference emerged between the laser and ultrasound groups, although laser treatment provided a much greater increase in the wound breaking strength than ultra- sound. Both treatments have beneficial effects on the inflamma- tory, proliferation, and maturation phases of wound healing. Both can be used successfully for decubitis ulcers and chronic wounds, in conjunction with conventional therapies such as debridement and daily wound caring. However, laser treatment was more effective than ultrasound in the first two phases of wound healing.

Key words: laser, physical medicine, physical therapy, rat, rehabilitation, ultrasound, wound healing.

Abbreviations: $\mathrm{GaAs}=$ gallium arsenide, $\mathrm{KCl}=$ potassium chloride, $\mathrm{PNL}=$ polymorphonuclear leukocyte. This material was based on work supported by The Experimental and Clinical Research Center of Erciyes University, Kayseri, Turkey.

Address all correspondence to Assoc. Prof. Dr. Hüseyin Demir; Erciyes Üniversitesi, Tp Fakültesi, FTR Anabilim Dal. 38039, Kayseri, Turkey; +90-352-437-4901, ext. 22077; fax: +90-352-437-5285; email: demirh@erciyes.edu.tr.

DOI: 10.1682/JRRD.2003.08.0131

INTRODUCTION

Wound healing is a complex process, and recently, rapid developments in the knowledge of its basic principles have been reported. Natural healing takes time, and humans quickly become impatient. As a result, open sores have been treated with medicines and a range of natural and synthetic materials in an attempt to speed healing.

However, problems related to wound healing are still the cause of significant morbidity and mortality $[1,2]$. In spinal cord injury and immobilization, one of the main problems is decubitis, or pressure ulcers. This condition causes not only morbidity but also mortality. Much time and money are spent treating this problem. Studies on wound healing have increased our knowledge and understanding of these pressure ulcers, which constitute an important clinical problem in rehabilitation medicine [3].

Most studies concerning wound healing focus on accelerating wound and soft tissue healing, obtaining normal wound breaking strength, and preventing keloid and scar formation [2]. Recently, some researchers concluded that some physical methods, including therapeutic ultrasound and laser treatments, accelerate and facilitate wound healing and increase scar quality [4-17].

Therapeutic ultrasound has been widely used over the past 50 years to treat many musculoskeletal complaints, including tendon injuries, pressure sores, venous ulcers, poor wound healing, lateral epicondylitis, herpes zoster, muscle damage, Dupuytren's contractures, and others. Since the 1960s, the effects and benefits of ultrasound on wound healing have been investigated by various studies $[4-7,16]$. Because many studies have produced conflicting findings, the clinical use of ultrasound for wound healing is still under investigation $[18,19]$. Although some investigators saw no acceleration in the repair of wounds with ultrasound treatment [19-21], positive results and treatment effects have been reported in studies of 
ultrasound treatment on tendon injuries, lateral epicondylitis, and wound healing [4-7,22,23]. In addition, the beneficial effects of laser treatment on wound healing and qualified scar formation have been reported by numerous studies [10-15,17,24,25], including our previous study [26].

In the literature, no comparison exists of ultrasound and laser treatments on the acceleration of wound healing and quality of scar formation. In this study, we investigated and compared the effects of ultrasound and laser treatments on the wound healing process through a randomized controlled trial.

\section{METHODS}

We used 124 healthy female Swiss-Albino rats, each 200 to $240 \mathrm{~g}$ and 8 to 10 months of age. The study was carried out at Erciyes University Experimental and Clinical Research Center. All rats were housed in metal cages maintained at $15 ?$ to $18 ?$ and fed standard rat chow and water. After making a $6 \mathrm{~cm}$ linear incision at the dorsal skin, we divided the rats randomly into 4 groups of 30 rats each. Four rats were used for initial trials. The treatment protocols used included ultrasound in Group I, control ultrasound in Group II, laser in Group III, and control laser in Group IV. In all groups, we performed biochemical and histopathologic evaluations on the 4th and 10th days, as well as a biomechanical test on the 25th day.

\section{Surgical Procedure}

After local preparation of the dorsal skin and general anesthesia of rats by ketamine $(60 \mathrm{mg} / \mathrm{kg}$, intraperitoneally), a $6 \mathrm{~cm}$ full-thickness linear incision was made $2 \mathrm{~cm}$ away from the dorsal midline including the panniculus carnosus. The incision was sutured with 5.0 prolene intradermally. The same investigator (SY) performed all surgical procedures.

\section{Treatment Methods and Group Formation}

The treatment was started in each group within 2 hours of the surgical procedure.

\section{Group I: Ultrasound Treatment}

An ultrasound device (model Sonopuls 463, Enraf-Nonius Co., The Netherlands) was used with a probe $8 \mathrm{~mm}$ in diameter and sterile Sonogel (Enraf-Nonius Co.). We applied a pulsed ultrasound (2 ms on, $8 \mathrm{~ms}$ off, and $0.5 \mathrm{~W} / \mathrm{cm}^{2}$ intensity) by a moving applicator technique, 5 minutes daily, for 10 days. An ultrasound intensity of $0.5 \mathrm{~W} / \mathrm{cm}^{2}$ minimized its thermal effect.

\section{Group II: Sham Ultrasound Treatment}

A procedure similar to the ultrasound treatment was applied with no current (sham method).

\section{Group III: Laser Treatment}

A gallium-arsenide (GaAs) laser device (model Laserpet 100, Petas Co., Turkey) with a probe $1 \mathrm{~cm}$ in diameter and 15 ?emission angle, at $904 \mathrm{~nm}$ wavelength, $6 \mathrm{~mW}$ average power, $1 \mathrm{~J} / \mathrm{cm}^{2}$ dosage, $16 \mathrm{~Hz}$ frequency, 10 minutes duration, was used continuously for 10 days by a stroking method.

\section{Group IV: Sham Laser Treatment}

A procedure similar to the laser treatment was applied with no current (sham method).

\section{Evaluations}

All wounds were cleaned with povidon-iodine solution every day, and all rats were housed in their metal cages. 
Ten rats in each group were killed with a 2 cc intracardiac potassium chloride $(\mathrm{KCl})$ injection on the 4th, 10th, and 25th days. We marked the incision as parts $a, b, c, d$, e, and $f$ (Figure). Full-thickness samples were obtained after the surgical process. Then parts $a$ and $c$ were used for histopathologic evaluation, parts $b$ and $d$ for biochemical evaluation, and parts $e$ and $f$ for biomechanical evaluation. Histopathologic and biochemical evaluations on the 4th and 10th days and a biomechanical evaluation on the 25th day were performed.
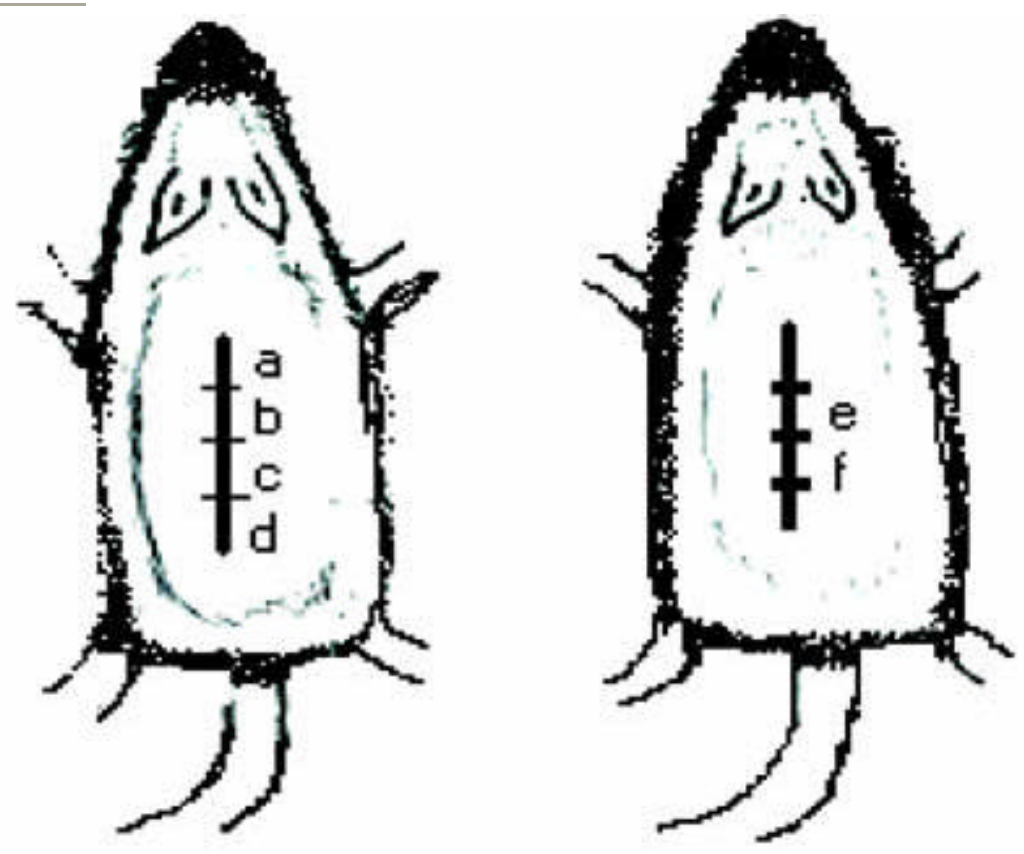

Figure.

Model of skin wound of rats (dorsal view). Incision divided into parts $a, b, c, d, e$, and $f$.

Slides were stained with hematoxylin and eosin for polymorphonuclear leukocytes (PNL), fibroblasts, and macrophages with the Young and Dyson method [6], Masson's trichrome for collagen density and arrangement with the Brown method, and toluidine blue for mast cells with the Weiss et al. method [27] for histopathologic analysis. Using the double-blind method, we measured the level of tissue hydroxyproline for biochemical analysis using the method of Reddy and Envemeka in parts $b$ and $d$ [28].

After sacrificing the rats with a $\mathrm{KCl}$ injection and removing the sutures, to evaluate the biomechanical parameter on the 25th day, we used a parallel surgical blade to excise two $10 \mathrm{~mm}$ strips, $6 \mathrm{~cm}$ long, in parts $e$ and $f$ of the wound, according to the method of Mustoe et al. [29]. We measured the wound breaking strength with a tensiometer (model 4411, Instron Inc., England) to get data to identify the maturation phase of the wound for our biomechanical evaluation with the blind method.

\section{Statistical Analysis}

We used a Mann-Whitney U-test for statistical analysis of all the parameters, except the collagen density and arrangement. A chi-square test was used to compare the collagen density and the arrangement of the groups.

\section{RESULTS}

A small amount of serohemorrhagic leakage was observed on wound edges within the first few days in the ultrasound, sham ultrasound, and sham laser treatment groups. The hairs were observed to grow on the 
7th day in the ultrasound, sham ultrasound, and sham laser treatment groups, and on the 5th day in the laser treatment group.

The duration of inflammatory phase decreased in the laser and ultrasound groups compared with the control groups $(p<0.05)$. Compared with ultrasound treatment, the laser treatment was found to be more effective, with more significant results $(p<0.05)$.

The proliferation phase was positively affected in the treatment groups by an increase in the level of hydroxy-proline and the number of fibroblasts, as well as stimulation of the collagen synthesis and the composition, compared with the control groups $(p<0.05)$. The laser treatment proved more effective than the ultrasound treatment in the proliferation phase $(p<0.05)$.

The laser treatment increased the mast cell count much more than the ultrasound treatment in the inflammatory phase $(p<0.05)$, although no statistically significant difference emerged in mast cell count between the laser and ultrasound groups in the proliferation phase $(p>0.05)$.

The wound breaking strength was significantly higher in the treatment groups than in the control groups ( $p$ $<0.05)$. No statistically significant difference was observed between the treatment groups $(p>0.05)$, although the laser treatment provided much more increase in the wound breaking strength than the ultrasound treatment.

The collagen density and the arrangement were significantly better in the treatment groups than in the control groups $(p<0.05)$, but no statistically significant difference existed between the treatment groups $(p>$ 0.05). Overall results are summarized in Tables 1 to 4.

Table 1.

Analysis of histopathologic and biochemical results on 4th day.

\begin{tabular}{lcccc}
\multicolumn{1}{c}{ Parameter } & $\mathbf{U S}^{*}(\mathbf{X} \pm \mathbf{S D})$ & $\mathbf{S U S}^{*}(\mathbf{X} \pm \mathbf{S D})$ & $\mathbf{L} *(\mathbf{X} \pm \mathbf{S D})$ & $\mathbf{S L} *(\mathbf{X} \pm \mathbf{S D})$ \\
PNL & $37.4 \pm 1.1$ & $62.2 \pm 1.7$ & $17.4 \pm 1.1$ & $61.0 \pm 5.2$ \\
Macrophages & $27.4 \pm 1.1$ & $27.0 \pm 1.6$ & $25.6 \pm 1.1$ & $35.6 \pm 0.9$ \\
Mast Cells & $16.0 \pm 1.2$ & $16.2 \pm 1.3$ & $24.2 \pm 0.8$ & $17.6 \pm 0.6$ \\
Fibroblasts & $66.2 \pm 1.3$ & $37.0 \pm 1.6$ & $82.6 \pm 2.1$ & $32.8 \pm 2.2$ \\
Hydroxyproline $(\mathrm{mg} / \mathrm{g})$ & $0.38 \pm 0.12$ & $0.08 \pm 0.03$ & $0.62 \pm 0.02$ & $0.14 \pm 0.04$
\end{tabular}

${ }^{*} n=10$

$p<0.05$ except for ultrasound treatment and sham ultrasound treatment macrophages and mast cells, where $p>0.05$.

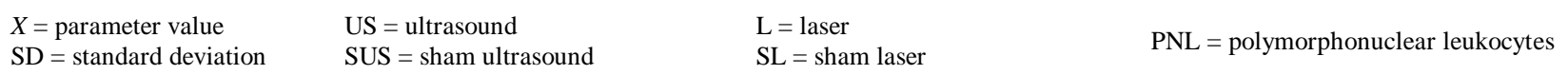

Table 2.

Analysis of histopathologic and biochemical results on 10th day.

\section{Parameter}

PNL

Macrophages

Mast Cells

Fibroblasts

Hydroxyproline (mg/g)

${ }^{*} n=10$

$p<0.05$

US $=$ ultrasound

\section{US* $(\mathrm{X} \pm \mathrm{SD})$}

$$
12.8 \pm 0.8
$$$$
17.2 \pm 0.8
$$$$
6.8 \pm 0.8
$$$$
82.0 \pm 1.6
$$$$
0.67 \pm 0.08
$$

SUS $=$ sham ultrasound

$\mathrm{L}=$ laser

$\mathrm{SL}=$ sham laser

SUS* $(\mathbf{X} \pm \mathbf{S D})$
$66.0 \pm 1.0$
$27.0 \pm 1.6$
$15.6 \pm 1.1$
$51.8 \pm 3.5$
$0.23 \pm 0.03$

$\mathbf{L}^{*}(\mathrm{X} \pm \mathrm{SD})$

$\mathrm{SL}^{*}(\mathrm{X} \pm \mathrm{SD})$

$8.6 \pm 1.5$

$43.2 \pm 1.8$

$17.4 \pm 1.1$

$27.4 \pm 0.9$

$6.2 \pm 0.8$

$22.8 \pm 0.8$

$113.2 \pm 4.1$

$53.0 \pm 2.8$

$1.01 \pm 0.13$

$0.22 \pm 0.01$

$X=$ parameter value

$\mathrm{SD}=$ standard deviation

$\mathrm{PNL}=$ polymorphonuclear leukocytes

Table 3.

Comparison of data on 4th and 10th days. 


\section{Parameter}

4th Day $(n=10)$

$\begin{array}{lc} & \text { US }(\mathbf{X} \pm \\ \text { PNL } & 37.4 \pm 1.1 \\ \text { Macrophages } & 27.4 \pm 1.1 \\ \text { Mast Cells } & 16.0 \pm \\ \text { Fibroblasts } & 66.2 \pm \\ \text { Hydroxyproline }(\mathrm{mg} / \mathrm{g}) & 0.38 \pm \\ p<0.05 \text { except for macrophages and mast cells, where } p & >0.05 . \\ \text { US }=\text { ultrasound } & \\ \mathrm{L}=\text { laser } & \\ X=\text { parameter value } & \end{array}$

$\begin{array}{ccc}\mathbf{L}(\mathbf{X} \pm \mathbf{S D}) & \mathbf{U S}(\mathbf{X} \pm \mathbf{S D}) & \mathbf{L}(\mathbf{X} \pm \mathbf{S D}) \\ 17.4 \pm 1.1 & 12.8 \pm 0.8 & 8.6 \pm 1.5 \\ 25.6 \pm 1.1 & 17.2 \pm 0.8 & 17.4 \pm 1.1 \\ 24.2 \pm 0.8 & 6.8 \pm 0.8 & 6.2 \pm 0.8 \\ 82.6 \pm 2.1 & 82.0 \pm 1.6 & 113.2 \pm 4.1 \\ 0.62 \pm 0.02 & 0.67 \pm 0.08 & 1.01 \pm 0.13\end{array}$

$\mathrm{SD}=$ standard deviation

$\mathrm{PNL}=$ polymorphonuclear leukocytes

Table 4.

Comparison of wound breaking strength on 25th day.

$\quad$ Parameter
Breaking Strength $(\mathrm{N})$
${ }^{*} n=10$
$p<0.05$
US $=$ ultrasound

DISCUSSION

$$
\begin{array}{cc}
\mathbf{U S}^{*}(\mathbf{X} \pm \mathbf{S D}) & \mathbf{S U S}^{*}(\mathbf{X} \pm \mathbf{S D}) \\
5.1 \pm 1.6 & 1.9 \pm 0.7 \\
\mathrm{SUS}=\text { sham ultrasound } \\
\mathrm{L}=\text { laser } \\
\mathrm{SL}=\text { sham laser }
\end{array}
$$

$\mathbf{L}^{*}(\mathbf{X} \pm \mathbf{S D})$
$6.8 \pm 1.3$
$X=$ parameter value
$\mathrm{SD}=$ standard deviation

$X=$ parameter value
$\mathrm{SD}=$ standard deviation
$\mathbf{S L}^{*}(\mathbf{X} \pm \mathbf{S D})$
$1.8 \pm 0.6$

Recently, some physical methods, including therapeutic ultrasound and laser treatments, were found to accelerate and facilitate wound healing and increase scar quality [4-17]. However, conflicting findings have been reported in some studies, and some investigators found no treatment effect on accelerating the repair of wounds [18-21].

Because treatment methods vary and some studies are poorly controlled or provide little detail on their protocols, attempts to determine efficacy are confounded. The possible mechanism through which ultrasound helps tissue repair is likely related to its mechanical effects, as opposed to the thermal effect $[30,31]$. Micromassage or ultrasonication of the tissue produces a change in membrane permeability and stimulates second messenger substance, such as calcium, across the cell membrane [31,32]. Then the proliferation of myogenic cells may be stimulated by these second messengers [33]. The anti-inflammatory effects of ultrasound have been shown in some studies $[6,8]$. This mechanism could be explained by the reduction of the macrophage number $[8,34]$. In our study, the macrophage number was found to be significantly decreased in the ultrasound group compared with its control group on the 10th day, which is consistent with the reported anti-inflammatory effect of ultrasound treatment.

Ultrasound has also been shown to effectively stimulate fibroblasts [34]. In some animal studies, researchers found that ultrasound at the intensities of $0.1 \mathrm{~W} / \mathrm{cm}^{2}$ and $0.5 \mathrm{~W} / \mathrm{cm}^{2}$ accelerates the inflammatory phase of repair $[6,9,35]$. This reported accelerated repair agrees with the findings from several other suggestions that low-dose ultrasound of approximately $0.5 \mathrm{~W} / \mathrm{cm}^{2}$ pulsed with a frequency of 1 or 3 $\mathrm{MHz}$ promotes wound healing [34-37]. Our treatment protocol included pulsed ultrasound with a dose of 0.5 $\mathrm{W} / \mathrm{cm}^{2}$ at a frequency of $1 \mathrm{MHz}$ for 5 days in the ultrasound group, a protocol that was applied in most studies. In the ultrasound group of our study, the duration of inflammatory phase decreased and the proliferation phase was positively affected by the increase in the level of hydroxyproline and the number of fibroblasts, as well as stimulation of the collagen synthesis and the composition, compared with its control group. These findings are consistent with the studies reporting the positive effects of ultrasound on wound healing $[4-7,30]$.

Laser treatment has also been studied in wound healing [10-15,17,24-26]. Currently, laser treatment is used for decubitis and diabetic ulcers, open wounds, venous ulcers, graft ulcers, incisions, lacerations, and burns. Studies in vivo and in vitro showed that laser treatment accelerated biochemical reactions, fibroblast activity, collagen metabolism, neovascularization, qualified scar formation, and wound formation [10$15,17,24-26]$. The issue of "significant" thermal change is controversial, although some studies conclude that the low-energy laser does not produce significant tissue temperature changes $[17,38]$. Therefore, no unanimous agreement exists on the thermal effects and the treatment protocol of laser treatment on wound 
healing, and more studies are required in this field. A wide variation exists in recommendations for the optimal energy for different conditions; the usual ranges are from 0.5 to $10 \mathrm{~J} / \mathrm{cm}^{2}$ [17]. Generally, a laser wavelength of 600 to $984 \mathrm{~nm}$ is used in physical medicine, and a laser wavelength of $632.8 \mathrm{~nm}$ helium neon and $904 \mathrm{~nm}$ GaAs are most frequently used in wound healing [10-15,17,26]. Therefore, we used a GaAs laser with a wavelength of $904 \mathrm{~nm}$ and power of $1 \mathrm{~J} / \mathrm{cm}^{2}$. With the laser treatment, the duration of inflammatory phase decreased and the level of hydroxyproline and the number of fibroblast increased, and also the collagen synthesis and the composition were stimulated in the proliferation phase compared with its control group. These findings are consistent with the literature.

Laser treatment has an antibacterial effect as well. Laser treatment has been reported to inhibit the proliferation of bacteria in cultures. We found a decreased number of macrophages in the laser treatment group compared with the sham laser treatment group, consistent with the literature. However, we did not find any previous study in the literature regarding the effects of laser treatment on the number of macrophages. Laser treatment also stimulates the phagocytic activity of leukocytes in vitro [39]. In our study, the PNL number increased in the laser treatment group compared with its control group. This finding indicates suppressed inflammation, which is desired in clean wound healing. Some researchers have reported that low-energy laser treatment decreased the duration of the inflammatory phase $[15,40]$.

When we compared these two modalities in the inflammatory phase, the laser treatment was more effective, with more significant results than the ultrasound treatment. The numbers of PNL and macrophages were decreased in the laser group compared with the ultrasound group, indicating that the laser treatment decreased the duration of inflammatory phase significantly more than the ultrasound treatment. We could not find any similar study comparing the effect of ultrasound and laser treatment on wound healing in rats in the literature. Mechanical stress is known to affect the collagen arrangement [41]. Tissue hydroxyproline level is accepted as an important parameter in the evaluation of collagen metabolism [42]. In our study, the proliferation phase was positively affected in the treatment groups by the increase in the level of hydroxyproline and the number of fibroblasts, as well as stimulation of the collagen synthesis and the composition, compared with their control groups. Compared with the ultrasound treatment, the laser treatment proved more effective in the proliferation phase.

The maturation or remodeling phase is the last and longest phase of wound healing. The most important development is the remodeling and maturation of collagen during this phase. The wound breaking strength can be used for the biomechanical evaluation of wound in this phase. Breaking strength increases significantly after the third week of wound healing, so we measured the breaking strength on the 25 th day. The wound breaking strength was significantly higher in the treatment groups than in the control groups, which is also consistent with the literature $[9,10,12,14]$. No statistically significant difference existed between the treatment groups, although the laser treatment provided much more increase in the wound breaking strength than the ultrasound treatment.

Our study showed that both ultrasound treatment and laser treatment have beneficial effects in the inflammatory, proliferation, and maturation phases of wound healing, compared with their control groups.

\section{CONCLUSION}

We conclude that both laser and ultrasound treatments can be used successfully for decubitis ulcers and chronic wounds, when used with conventional therapies such as debridment and daily wound caring. The laser treatment, however, was considered more effective than the ultrasound treatment in the first two phases of wound healing.

\section{REFERENCES}

1. Colver GB, Priestley GC. Failure of a helium-neon laser to affect components of wound healing in vitro. Br J Dermatol. 1989;121(2):179-86.

2. Peacock EE, Cohen IK. Wound healing. In: McCarthy JG, May JW, Littler JW, editors. Plastic surgery. Philadelphia: WB Saunders Co.; 1990. p. 161-85.

3. Colen SR. Pressure sores. In: Goodgold J, editor. Rehabilitation medicine. St. Louis (MO): CV Mosby Co; 1988. p. 167-83.

4. Paul BJ, Lafrayya CW, Dawson AR, Babb E, Bullock F. Use of ultrasound in the treatment of pressure sores in patients with spinal cord injury. Arch Phys Med Rehabil. 1960;41:438-40. 
5. Dyson M, Pond JB. The effect of pulsed ultrasound on tissue regeneration. Physiotherapy. 1970;56:136-42.

6. Young SR, Dyson M. Effect of therapeutic ultrasound on the breaking of full-thickness excised skin lesions. Ultrasonics. 1990;28:170-80.

7. Byl NN, McKenzie AL, West JM, Whitney JD, Hunt TK, Sheuenstuhl HA. Low-dose ultrasound effects on wound healing: A controlled study with Yucatan pigs. Arch Phys Med Rehabil. 1992;73:656-64.

8. Young SR, Dyson M. The effect of therapeutic ultrasound on angiogenesis. Ultrasound Med Biol. 1990;16:261-69.

9. Taskan I, Özyazgan I, Tercan M, Kardas HY, Balkanli S, Saraymen R, Zorlu U, Ozugul Y. A comparative study of the effect of ultrasound and electrostimulation on wound healing in rats. Plast Reconstr Surg. 1997;100(4):966-72.

10. Abergel P, Lyons RF, Castel JC, Dwyer RM, Uitto J. Biostimulation of wound healing by lasers: experimental approaches in animal models and in fibroblast cultures. J Dermatol Surg Oncol. 1997;13:12733.

11. Bisht D, Gupta SC, Misra V, Mital VP, Sharma P. Effect of low intensity laser radiation on healing of open skin wounds in rats. Indian J Med Res. 1994;100:43-46.

12. Lyons RF, Abergel P, White R. Biostimulation of wound healing in vivo by a helium-neon laser. Ann Plast Surg. 1987; 18:47-51.

13. Conlan M, Rapley JW, Cobb CM. Biostimulation of wound healing by low-energy laser irradiation: A review. J Clin Periodont. 1996;23:492-96.

14. Bravermen B, McCarthy RJ, Ivankovich, DE, Forde DE, Overfield M, Bapna MS. Effect of helium-neon and infrared laser irradiation on wound healing in rabbits. Lasers Surg Med. 1989;9:50-58.

15. Ghamsari SM, Taguchi K, Abe N, Acorda JA, Sato M, Yamada H. Evaluation of low level laser therapy on primary healing of experimentally induced full thickness teat wounds in dairy cattle. Vet Surg. 1997;26:114-20.

16. Dyson M. Role of ultrasound in wound healing. In: Kloth LC, McCulloch JM, Feedar JA, editors. Wound healing: Alternatives in management. Philadelphia (PA): FA Davis Co; 1990. p. 255-76.

17. Low J, Reed A. Laser therapy. In: Low J, Reed A. editors. Electrotherapy explained: principle and practice. London: Butterworth Heinemann Ltd; 1993. p. 299-313.

18. Nussbaum E, Biemann I, Mustard B. Comparison of ultrasound/ultraviolet-C and laser for treatment of pressure ulcers in patient with spinal cord injury. Phys Ther. 1994; 79:812-23.

19. ter Riet G, Kessels AG, Knipschild PG. A randomized clinical trial of ultrasound in the treatment of pressure ulcers. Phys Ther. 1996;76(12):1301-11.

20. Lundeberg T, Northstrom F, Brodda-Jansen G, Eriksson SV, Kjartansson J, Samuelson UE. Pulsed ultrasound does not improve healing of venous ulcers. Scand J Rehabil Med. 1990;22:195-97.

21. Cambier DC, Vanderstraeten GG. Failure of therapeutic ultrasound in healing burn injuries. Burns. 1997;23:248-49.

22. Gan BS, Huys S, Sherebrin MH, Scilley CG. The effects of ultrasound treatment on flexor tendon healing in the chicken limb. J Hand Surg (Br). 1995;20:809-14.

23. Lundeberg T, Abrahamsson P, Haker E. A comparative study of continuous ultrasound, placebo ultrasound and rest in epicondylalgia. Scand J Rehabil Med. 1998;20:99-101.

24. Stadler I, Lanzafame RJ, Evans R, Narayan V, Dailey B, Buehner N, Naim JO. 830-nm irradiation increases the wound tensile strength in a diabetic murine model. Lasers Surg Med. 2001;28(3):220-26.

25. Simunovic Z, Ivankovich AD, Depolo A. Wound healing of animal and human body sport and traffic accident injuries using low-level laser therapy treatment: a randomized clinical study of seventy-four patients with control group. J Clin Laser Med Surg. 2000;18:67-73.

26. Demir H, Balay H, Kirnap M. A comparative study of the effects of laser and electrostimulation on experimental wound healing in rats. J Rehabil Res Dev. 2004;41(2):147-54.

27. Weiss DS, Eaglstein, WH, Falanga V. Exogenous electric current reduce the formation of hypertrophic scars. J Dermatol Surg Oncol. 1989;15:1272-75.

28. Reddy GK, Envemeka CS. A simplified method for the analysis of hydroxyproline in biological tissues. Clin Biochem. 1996;29:225-29.

29. Mustoe TA, Weber DA, Krukowski M. Enhanced healing of cutaneous wounds in rats using beads with positively charged surfaces. Plast Reconstr Surg. 1992;89:891-99.

30. Karnes JL, Burton HW. Continuous therapeutic ultrasound accelerates repair of contraction-induced skeletal muscle damage in rats. Arch Phys Med Rehabil. 2002;83:1-4. 
31. Dinno MA, Dyson M, Young SR, Mortimer AJ, Hart J, Cum L. The significance of membrane changes in the safe and effective use of therapeutic and diagnostic ultrasound. Phys Med Biol. 1989;34:1543-52.

32. Moritmer AJ, Dyson M. Effect of therapeutic ultrasound on calcium uptake in fibroblasts. Ultrasound Med Biol. 1988; 14:499-506.

33. Mauro A. Satellite cell of skeletal muscle fibers. J Biophys Biochem Cytol. 1961;9:493-95.

34. Young SR, Dyson M. Macrophage responsiveness to therapeutic ultrasound. Ultrasound Med Biol. 1990;16:809-16.

35. El-Batouty MF, El-Gindy M, El-Shawaf I, Bassioni N, El-Ghaweet A, El-Eman A. Comparative evaluation of the effects of ultrasonic and ultraviolet irradiation on tissue regeneration. Scand $\mathrm{J}$ Rheumatol. 1986;15:381-86.

36. Byl NN, McKenzie A, Wong T, West J, Hunt TK. Incisional wound healing: a controlled study of low and high dose ultrasound. J Orthop Sports Phys Ther. 1993;18:619-28.

37. Lowe AS, Walker MD, Cowan R, Baxter D. Therapeutic ultrasound and wound closure: Lack of healing effect on X-ray irradiated wounds in murine skin. Arch Phys Med Rehabil. 2001;82:1507-11.

38. Weber DC, Brown AW. Physical agent modalities. In: Braddom RL, editor. Physical medicine and rehabilitation. Philadelphia: WB Saunders Co.; 1996. p. 449-64.

39. Cummings J. Role of light in wound healing. In: Kloth LC, McCulloch JM, Feedar JA, editors. Wound healing: Alternatives in management. Philadelphia (PA): FA Davis Co; 1990. p. 287-94.

40. Young S, Bolton P, Dyson M, Harvey W, Diamantapoulos C. Macrophage responsiveness to light therapy. Lasers Surg Med. 1989;9:497-505.

41. Dumphy JE. Modern biochemical concepts on the healing wound. In: Dumphy JE, editor. Wound healing. New York: Medcom; 1974. p. 22-31.

42. Kloth LC, Miller KH. The inflammatory response to wound healing. In: Kloth LC, McCulloch JM, Feedar JA, editors. Wound healing: Alternatives in management. Philadelphia (PA): FA Davis Co; 1990. p. 3-13. Submitted for publication August 21, 2003. Accepted in revised form November 5, 2003. 